16

\title{
Дистанционная регистрация следа судна по проявлениям на морской поверхности и приповерхностном слое морской среды и атмосферы
}

\author{
(C) В.Н. Носов ${ }^{1}$, С.Б. Каледин ${ }^{2}$, С.Г. Иванов ${ }^{1}$, В.И. Тимонин ${ }^{2}$ \\ ${ }^{1}$ Институт геохимии и аналитической химии им. В.И. Вернадского Российской академии наук (ГЕОХИ РАН), \\ 119991 Москва, Россия \\ ${ }^{2}$ МГТУ им. Н.Э. Баумана, \\ 105005 Москва, Россия \\ e-mail: sbkaledin@mail.ru
}

Поступила в редакцию 23.05.2019 г.

В окончательной редакции 23.05.2019 г.

Принята к публикации 04.06.2019 г.

Рассмотрены вопросы регистрации проявлений воздействий гидродинамических возмущений на три среды: морскую поверхность, приповерхностный слой и приводную атмосферу. Для исследований использованы три метода и аппаратура для их реализации в виде: сканирующего лазерного локатора, фотометра яркости моря и аэрозольного лидара упругого рассеяния. Экспериментальные исследования проводились в натурных условиях Черноморского полигона. Источником гидродинамических возмущений в виде отстающего следа являлось надводное судно. Анализ полученных результатов показал достаточную эффективность использованных методов и аппаратуры для регистрации проявлений следа судна в трех средах.

Ключевые слова: дистанционное оптическое зондирование, поверхностное морское волнение, приводный аэрозоль, гидродинамический источник возбуждения.

DOI: $10.21883 /$ OS.2019.10.48366.165-19

\section{Введение}

Изучение процессов и явлений в Мировом океане давно интересует исследователей, в частности, с точки зрения обнаружения и регистрации слабых гидродинамических возмущений (ГДВ), вызванных разными источниками. Такие возмущения чаще наблюдаются в виде косвенных проявлений изменения характеристик и параметров в водной толще, на поверхности и в приповерхностном слое атмосферы [1-4]. Одним из наиболее удобных для изучения проявлений различного рода ГДВ является след судна. Движущееся судно является генератором как волновых, так и турбулентных возмущений морской среды, присущих многим гидродинамическим источникам естественного и искусственного происхождения [5,6]. Среди большого набора разных методов исследования наиболее востребованы и перспективны дистанционные радиолокационные и оптические способы [7-11]. С их помощью удается дистанционно получать информацию о состоянии названных сред. Однако радиолокационные методы, обладающие известными достоинствами, уступают лазернооптическим методам в точности и разрешающей способности. Кроме того, взаимодействие радиоволн с морской поверхностью часто носит резонансный характер, что ограничивает возможности регистрации. В связи с этим применение лазерно-оптических способов исследования явлений в морской среде является, на наш взгляд, весьма актуальным и перспективным направлением.

\section{Постановка задачи}

Перспективные оптические системы дистанционного изучения морской среды должны обеспечивать высокое пространственное разрешение, обладая при этом необходимой энергетической чувствительностью. В связи с этим возникает вопрос выбора и обоснования наиболее эффективных методов дистанционного оптического зондирования состояния трех сред: взволнованной морской поверхности, приповерхностной водной толщи и приводного аэрозоля. Данные методы должны быть достаточно просты в технической реализации. Немаловажной задачей является разработка алгоритмов и программная реализация методов обработки информации и выделения важнейших информативных признаков.

\section{Основные методы исследования}

Для исследования проявлений воздействия (ГДВ) на морской поверхности может быть использован известный метод сканирования узким лазерным лучом [12]. Метод лазерного сканирования заключается в регистрации и последующей обработке импульсов излучения, возникающих при отражении лазерного луча от морской поверхности, в моменты, когда нормаль к водной поверхности в точке падения луча совпадает с осью освещающего пучка.

Авторами настоящей работы метод сканирования морской поверхности узким лазерным лучом был положен в основу принципа действия судового лазерного 


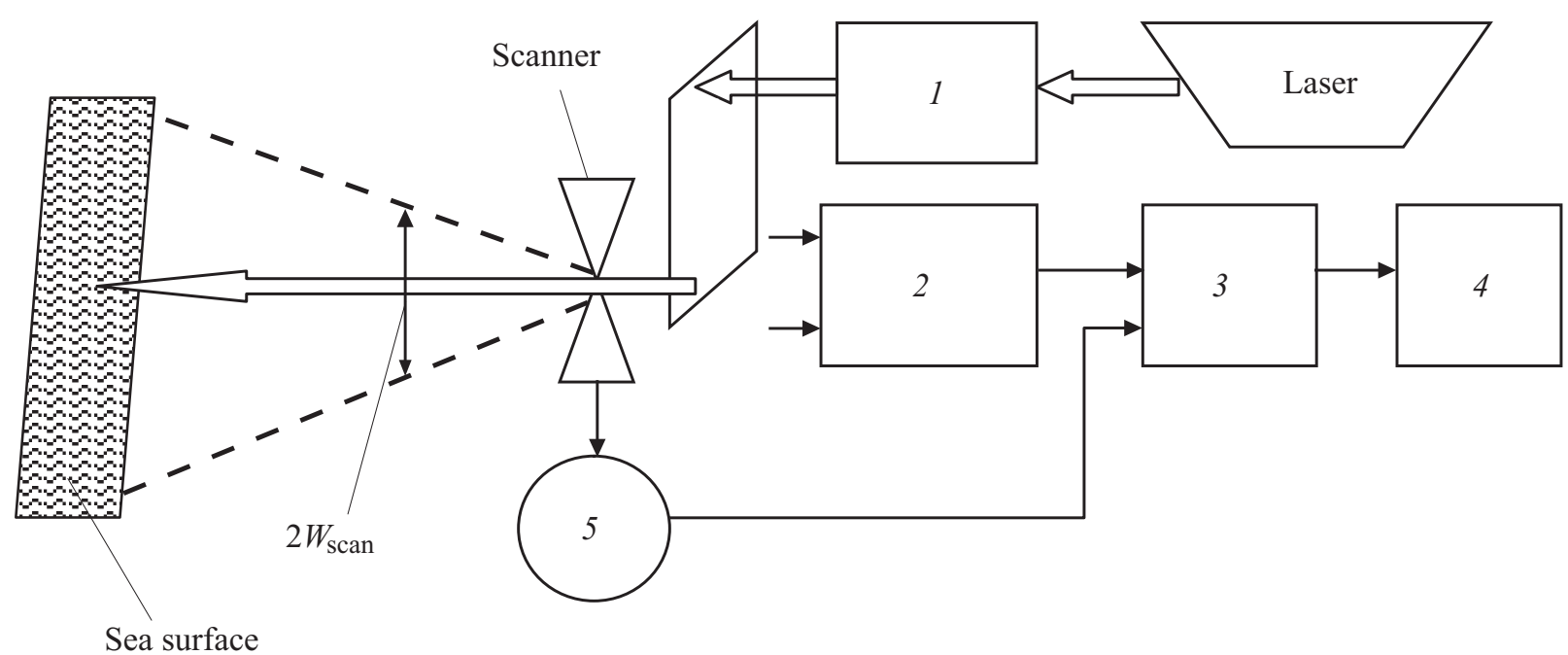

Рис. 1. Структурная схема морского сканирующего локатора: 1 - формирующая оптическая система, $2-$ фотоприемное устройство, 3 - аналого-цифровой преобразователь, 4 - персональный компьютер, 5 - синхродатчик.

локатора (СЛЛ) [13,14]. В состав локатора входят две оптические системы - канал лазерной подсветки и оптико-электронный приемный канал. Оптические оси обоих каналов коаксиально объединены, что значительно упрощает процесс пространственного сканирования и устраняет ошибки, связанные с параллаксом (рис. 1).

При сканировании морской поверхности в пределах угла $2 W_{\text {scan }}$ поперек направления движения носителя регистрируются сигналы, вызванные бликовым отражением от поверхности. Из-за большой линейной скорости сканирования лазерного пучка на водной поверхности регистрируемые фотосигналы имеют форму коротких импульсов. Основными параметрами сигналов являются: амплитуда импульсов, временные интервалы между импульсами и угол относительно вертикали в момент регистрации блика.

Амплитуда импульсов определяется интенсивностью засветки и размером отражающей поверхности. Случайная форма морской поверхности не позволяет точно определить размеры бликующей зоны, поэтому удобнее использовать понятие эквивалентного радиуса сферической поверхности согласно формуле (1)

$$
R_{e q}=\sqrt{\frac{4}{\pi} \frac{\mu \Phi_{t h r} A_{\text {light }}}{\rho \tau \tau_{\text {atm }} \Phi_{\text {las }}} \frac{l}{D_{\text {lens }}}}
$$

где $\mu$ - отношение сигнал/шум, $\rho=0.02-$ коэффициент отражения водной поверхности, $\Phi_{t h r}-$ пороговая чувствительность ФПУ, $A_{l i g h t}-$ площадь освещенной зоны на морской поверхности, $\tau_{a t m}-$ коэффициент пропускания атмосферы на трассе, $\tau-$ коэффициент пропускания оптической системы, $\Phi_{\text {las }}-$ мощность лазера, $l$ - длина трассы, $D_{\text {lens }}$ - диаметр зрачка объектива приемной системы.

Временной интервал между импульсами определяется пространственными масштабами волн вдоль трассы сканирования. Угол визирования, под которым регистрируется заданная точка, связан с уклонами волнения. Используя временные интервалы и амплитудные данные принимаемых электрических импульсов, можно получить гистограммы распределений расстояний между зеркальными бликами (определяемых масштабами волнения) и радиусов кривизны водной поверхности.

Изменение концентрации приводного аэрозоля [15-17] может быть зарегистрировано различными способами. В настоящей работе авторами для регистрации рассеяния лазерного излучения на аэрозоле была выбрана лидарная схема, заключающаяся в регистрации интенсивности обратного светорассеяния. Применительно к поставленной задаче проводимого эксперимента оптимальной была принята бистатическая схема аэрозольного лидара (рис. 2).

Схема аэрозольного лидара (АЛ) содержит два канала: лазерный канал модулированной подсветки и приемную оптико-электронную систему, разнесенные на величину базы $B$. Место пересечения оптических осей определяет ту область пространства $X$, состояние которой анализируется. Амплитуда фотосигнала зависит от оптических параметров аэрозоля (концентрации частиц, их дисперсного состава и т.д.), которые влияют на светорассеяние. Такая лидарная схема позволяет на дистанции $L$ регистрировать изменения интегрального рассеяния в области $X$, что определяет пространственное разрешение. Для повышения чувствительности аэрозольного лидара использован принцип синхронного накопления при обработке фотосигналов.

Регистрация изменения состояния приповерхностного слоя моря осуществлялась с помощью двухканального фотометра яркости моря (ФЯМ) (рис. 3). В фотометре измеряется восходящая яркость моря в дневных условиях $B_{M}(\lambda)$ на двух выбранных длинах волн 440 и $540 \mathrm{~nm}$ и затем вычисляется усредненное отноше- 


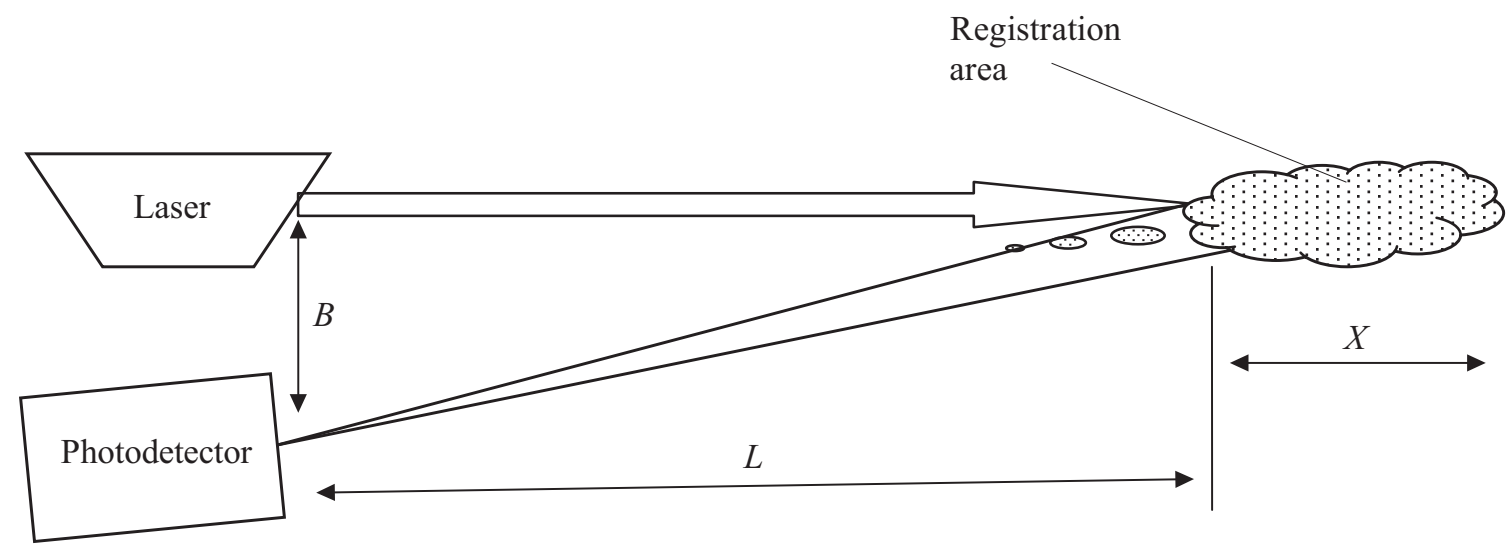

Рис. 2. Схема регистрации аэрозольного рассеяния.

ние этих яркостей $I=B_{M}(440) / B_{M}(540)[18-21]$. Длина волны $\lambda_{1}=440 \mathrm{~nm}$ находится вблизи максимума полосы поглощения хлорофилла „а“, содержащегося в фитопланктоне. Длина волны $\lambda_{2}=540 \mathrm{~nm}$ попадает в спектральный диапазон, где поглощения хлорофилла „а“ отсутствует. Величина отношения яркостей $I$ коррелирует с содержанием фитопланктона в приповерхностном слое моря, концентрация которого меняется при воздействии ГДВ. По этой причине при обработке результатов эксперимента наряду с анализом параметров $B_{M}(\lambda)$ исследовалась и величина их отношения $I$. В ряде случаев ее анализ позволяет уменьшить флуктуации полезного сигнала, связанные с морским волнением.

Техническая реализация и проведение исследований

Макеты приборов, реализующие названные методы, были установлены на борту научно-исследовательского судна. СЛЛ размещался на выносной консоли в носовой части судна, чтобы регистрировать морское волнение в невозмущенной области. ФЯМ и АЛ располагались на высоте $8 \mathrm{~m}$ за бортом. Все приборы установлены на стабилизирующих устройствах для уменьшения влияния качки судна.

Постановщиком гидродинамических возмущений являлся большой гидрографический катер БГК-889 водоизмещением $120 \mathrm{t}$ (рис. 4). Он создавал поверхностный след, двигаясь со скоростью около $6 \mathrm{kn}$.

В ходе экспериментов научно-исследовательское судно с приборами пересекало след судна-постановщика с определенной временной задержкой. При этом регистрировались сигналы до пересечения следа (фоновый участок) и в зоне следа. Экспериментальные натурные исследования проводились в акватории Черного моря при волнении моря до 3 баллов.

\section{Полученные результаты и обсуждение}

Экспериментальные данные, полученные при пересечении следа судна БГК-889 с возрастом около $100 \mathrm{~s}$, были статистически обработаны с помощью гистограммного анализа лазерных импульсов СЛЛ, отраженных от морской поверхности. Для каждого из временных интервалов составлялись две выборки: одна состояла из длин временных интервалов (в тысячных долях секунд) между начальными фронтами импульсов, а другая из максимальных значений амплитуд (напряжений) импульсов. Для этих выборок строились ненормированные гистограммы. Ниже представлены примеры характерных гистограмм, полученных после обработки.

Гистограммы временных интервалов представлены на рис. 5, $a, b$. По оси абсцисс отложен временной интервал между импульсами в долях $0.1 \mathrm{~ms}$, определяемый частотой оцифровки сигналов $10 \mathrm{kHz}$, использованной в АЦП. Из представленных гистограмм видно, что наибольшие изменения в гистограммах при пересечении следа БГК-889 происходят в области малых временных интервалов между импульсами СЛЛ в диапазоне 0-5 ms. Число импульсов в этом интервале за $6 \mathrm{~s}$ до пересечения составляет 90-97, а число импульсов в области пересечения - 54 .

Аналогичным образом изменяются и гистограммы амплитуд сигналов СЛЛ. Вне следа БГК-889 (за 6s до пересечения) число импульсов СЛЛ с наименьшими амплитудами в 2 раза превышает число импульсов из этого же диапазона в области следа (рис. $6, a, b)$.

Полученные результаты убедительно свидетельствуют об эффективности метода сканирования морской поверхности узким лазерным пучком для обнаружения изменения характеристик морского волнения под действием ГДВ в виде следа судна.

При обработке сигналов ФЯМ и АЛ рассчитывались средние значения по каждым двумстам сигналам АЦП, работающего при частоте оцифровки $10 \mathrm{kHz}$. На рис. 7, $a, b$ изображены гистограммы амплитуд сигналов канала А на временных отрезках вне и в области пересечения следа БГК-889. Данные гистограмм свидетельствуют о смещении значений амплитуд сигналов ФЯМ в сторону малых значений при пересечении следа судна. 


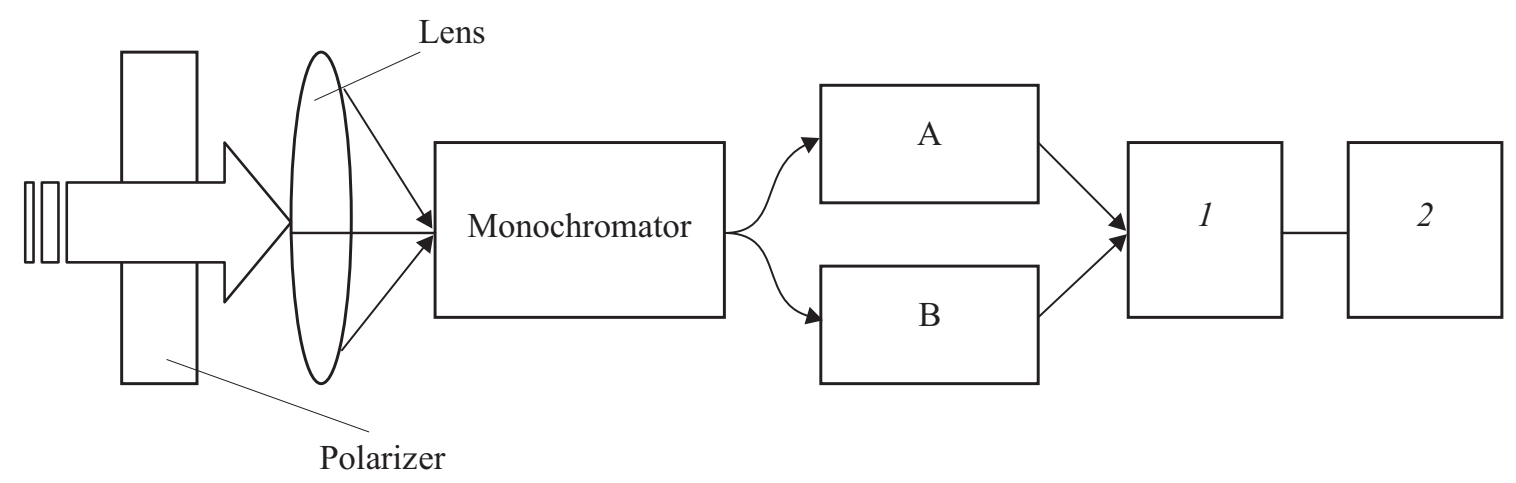

Рис. 3. Структурная схема фотометра яркости моря: А и В - фотоприемные устройства для регистрации сигналов на длинах волн 440 и $540 \mathrm{~nm}, 1$ - аналого-цифровой преобразователь, 2 - персональный компьютер.

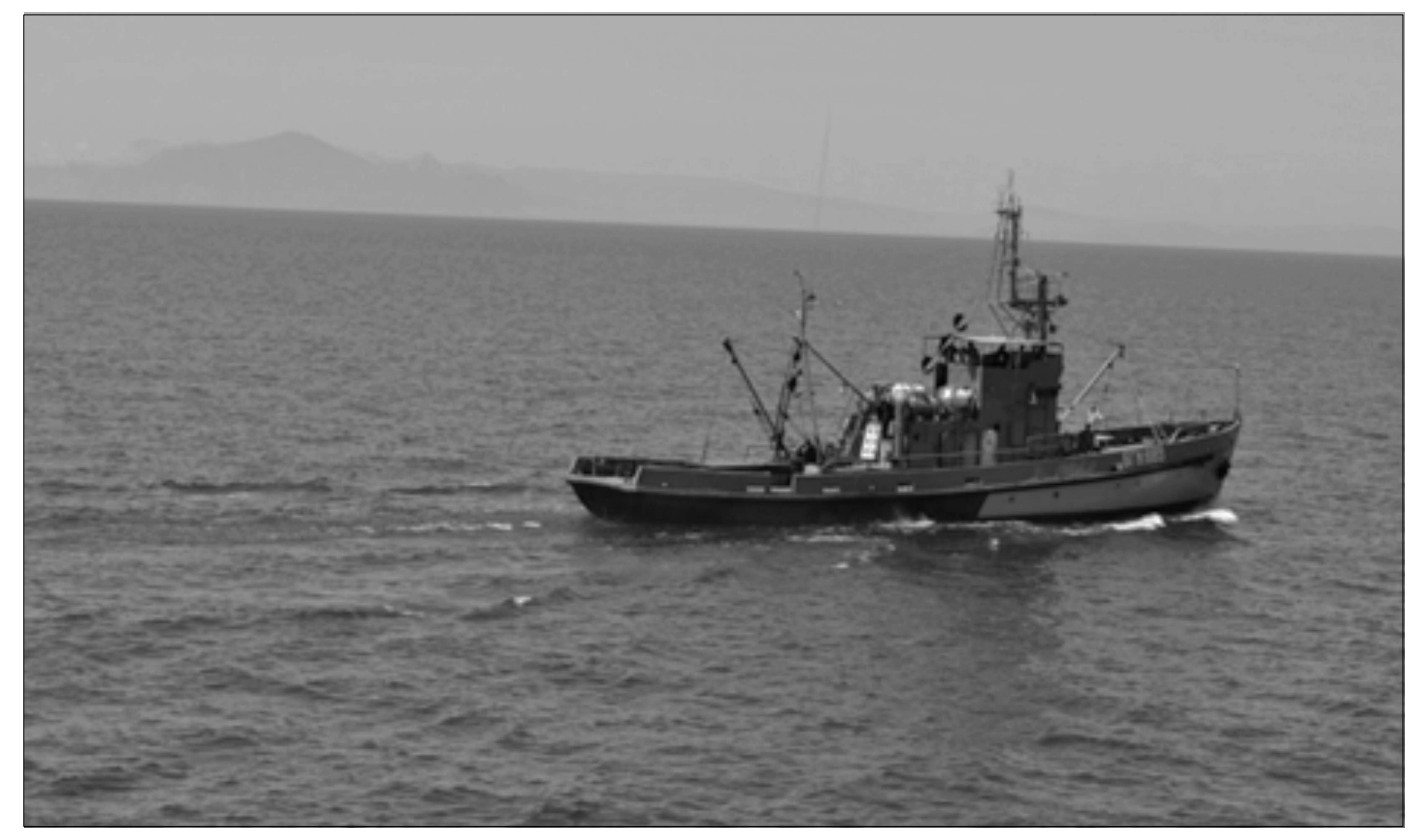

Рис. 4. Судно корабельного обеспечения БГК-889.
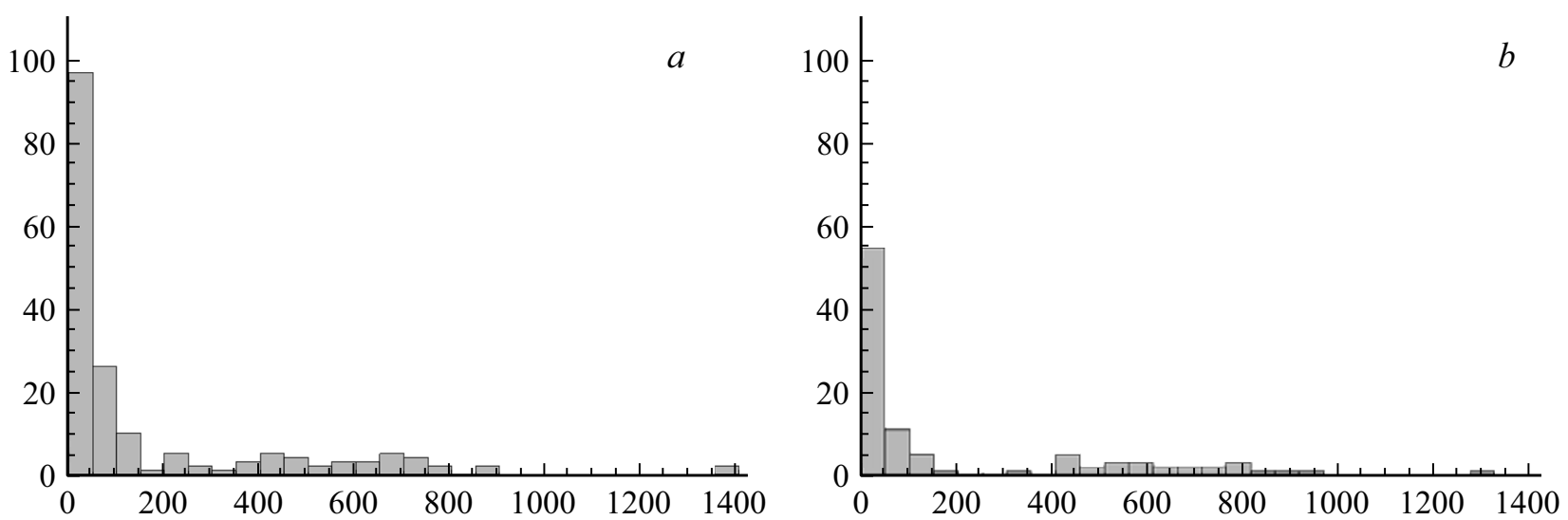

Рис. 5. Гистограммы временных интервалов между импульсами СЛЛ за $6 \mathrm{~s}$ до $(a)$ и в момент пересечения следа $(b)$. 

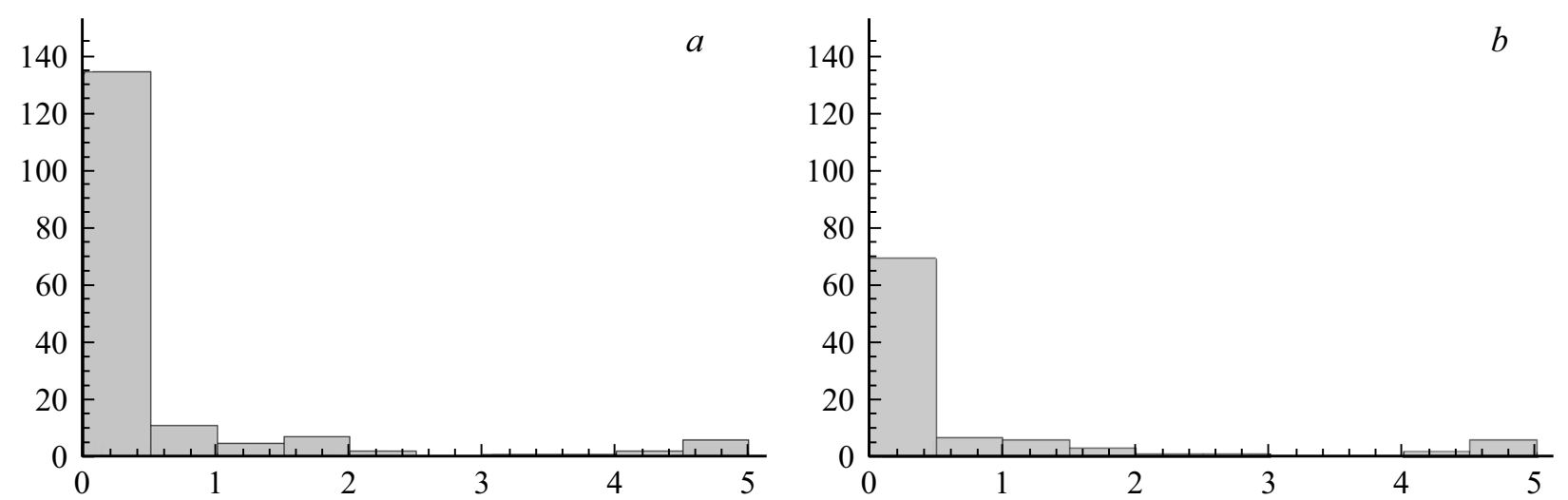

Рис. 6. Гистограммы амплитуд импульсов СЛЛ за $6 \mathrm{~s}$ до $(a)$ и в момент пересечения следа $(b)$.
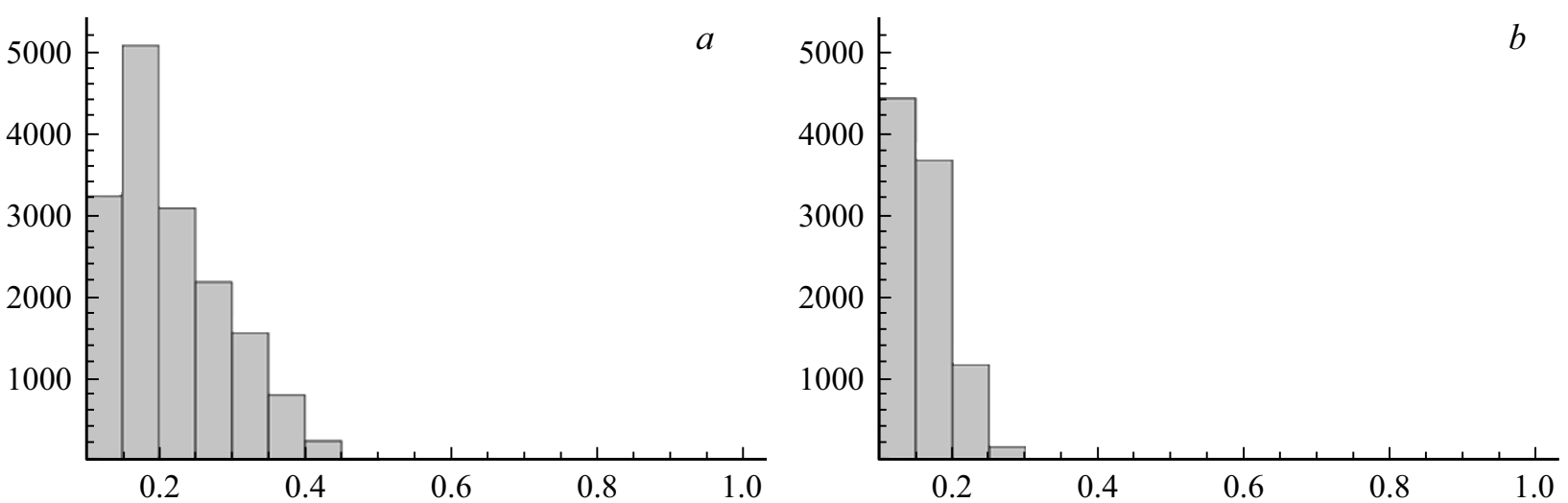

Рис. 7. Гистограммы амплитуд ФЯМ в канале А за промежуток времени $6 \mathrm{~s}$ вне следа $(a)$ и при пересечении следа судна $(b)$.

$a$

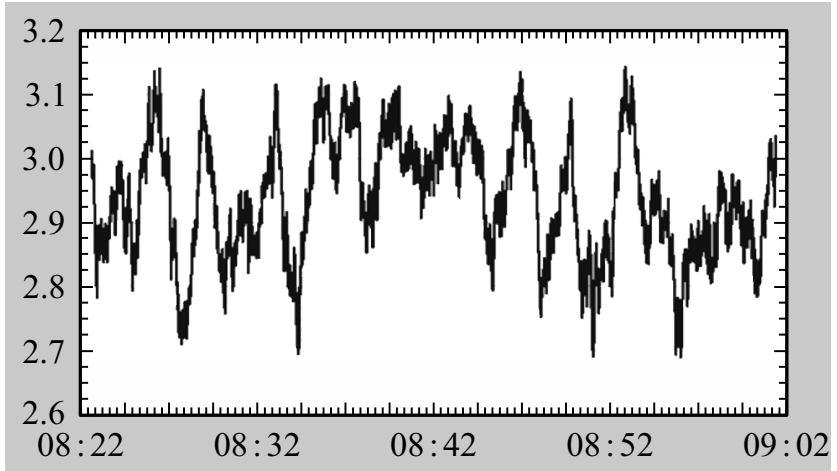

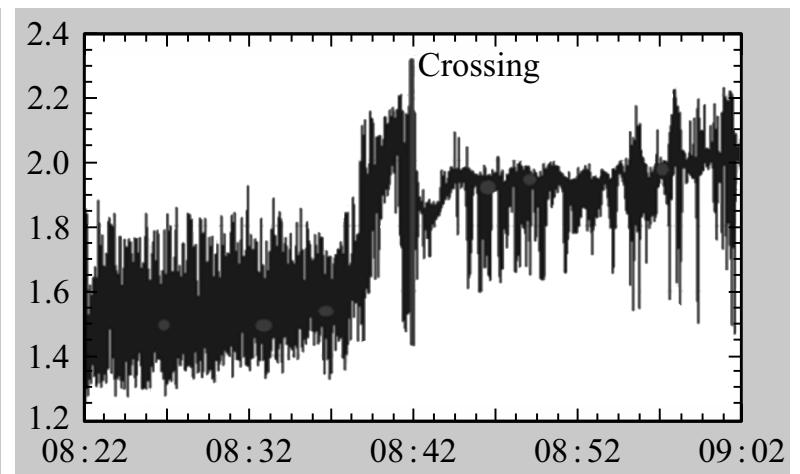

Рис. 8. Регистрограммы сглаженных амплитуд сигнала АЛ $(a)$ и отношения яркостей моря $I(\Phi Я М)(b)$ при пересечении следа галсом продолжительностью $40 \mathrm{~min}$ (момент пересечения оси следа $-8 \mathrm{~h} 42 \mathrm{~min}$ ).

Момент пересечения следа судна приборами ЛОА фиксировался не только на близких и коротких временных интервалах, но и при анализе сигналов на длительных участках трасс (галсов) носителя аппаратуры. На рис. $8, a, b$ показаны регистрограммы бегущих средних сигнала аэрозольного лидара и отношения $I$ сигналов ФЯМ на длинах волн $\lambda_{1}, \lambda_{2}$ при следовании судном-носителем прямолинейным курсом в течение $40 \mathrm{~min}$. Предполагаемый момент пере- сечения следа располагался в середине пройденного участка.

Обоими приборами зафиксированы аномальные изменения в регистрограммах сигналов, произошедшие в момент пересечения предполагаемого следа судна (особенно это проявляется в параметре $I$ сигналов ФЯМ). Важно отметить, что аномальные проявления отмечены приборами в одно и то же время, что повышает достоверность обнаружения следа судна. 


\section{Заключение}

Проведенные экспериментальные исследования возможностей предложенных лазерно-оптических методов показали, что данные методы могут с успехом использоваться для дистанционной регистрации различных процессов, происходящих в толще океана по слабоконтрастным проявлениям на морской поверхности и приповерхностным слоям морской среды и атмосферы, а их совместное применение позволяет существенно повысить достоверность получаемых результатов.

\section{Конфликт интересов}

Авторы заявляют, что у них нет конфликта интересов.

\section{Список литературы}

[1] Филлипс О.М. Динамика верхнего слоя океана. Л.: Гидрометеоиздат, $1980.320 \mathrm{c}$.

[2] Оптика океана и атмосферы / Отв. ред. Шифрин К.С. М.: Наука, 1981. $230 \mathrm{c}$.

[3] Монин А.С., Краситский В.П. Явления на поверхности океана. Л.: Гидрометеоиздат, 1985. $336 \mathrm{c.}$

[4] Оптика океана. Прикладная оптика океана. Т. 2 / Отв. ред. Монин А.С. М.: Наука, 1983. 263 с.

[5] Ермаков С.А., Капустин И.А. // Изв. РАН ФАО. 2010. T. 46. № 4. C. $565-570$.

[6] Баханов В.В., Горячкин Ю.Н., Корчагин Н.Н., Репина И.А. // Докл. РАН. 2007. Т. 414. № 1. С. 111-115.

[7] Шилин Б.В., Шубина М.А. // Геодезия и картография. 2000. № 9. C. $50-57$.

[8] Методы, процедуры и средства аэрокосмической компьютерной радиотомографии приповерхностных областей Земли / Под ред. Нестерова С.В., Шамаева А.С., Шамаева С.И., М.: Научный мир, 1996. 272 с.

[9] Дистанционный контроль верхнего слоя океана / Opлов В.М., Самохвалов И.В., Белов М.Л. и др. Новосибирск: Наука, 1991. 149 с.

[10] Оптические методы изучения океанов и внутренних водоемов, Новосибирск: Наука, 1979.

[11] Оптико-электронные методы изучения аэрозолей / Беляев С.П., Никифоров Н.К., Смирнов В.В., Щелчков Г.И. М.: Энергоиздат, 1981. 232 с.

[12] Ву Ж., Хаймбах С.П., Хсу Ю.Л. // Приборы для научных исследований. 1981. № 8. С. 120-126.

[13] The Use of Laser Scanning Locators for the Study of Statistical Characteristics of Sea Waves / Nosov V.N., Pashin S.Yu., Zosimov V.V. et. al. // Laser Physics. 1993. V. 3. N 1. P. 209-213.

[14] Носов В.Н., Зосимов В.В. // Вопросы судостроения. Сер. Акустика. 1983. В. 17. С. 28-32.

[15] Райст П. Аэрозоли. Введение в теорию. Пер. с англ. М.: Мир, 1987. $280 \mathrm{c.}$

[16] Nosov V.N., Gorelov A.M., Kaledin S.B., Kuznetsov V.A., Leonov S.O., Savin A.S. // Dokl. Earth Sci. 2010. V. 433(1). P. 920-921.

[17] Nosov V.N., Kaledin S.B., Gorelov A.M., Leonov S.O., Kuznetsov V.A., Pogonin V.I., Savin A.S. // Dokl. Earth Sci. 2012. V. 442(2). P. 247-248.
[18] Кельбалиханов Б.Ф. Гидрооптические исследования в водах Мирового океана. Сыктывкар, 1992. 126 с.

[19] Гинзбург А.И., Костяной А.Г., Кривошея В.Г., Незлин Н.П., Соловьёв Д.М., Станичный С.В., Якубенко В.Г. // Океанология. 2000. Т. 40. № 3. C. 344-356.

[20] Карабашев Г.С., Евдошенко М.А., Шеберстов С.В. // Океанология, 2005. Т. 45. № 2. С.182-192.

[21] Артемьев В.А., Буренков В.И., Вортман М.И., Григорьев А.В., Копелевич О.В., Храпко А.Н. // Океанология, 2000. T. 40. № 1. C. $148-155$. 